\title{
Metabolomics and fertility in cattle: A promising predictor
}

\author{
Trudee Fair \\ School of Agriculture \& Food Science, University College Dublin, Ireland.
}

\begin{abstract}
Summary
During her lifetime, the ovarian environment of female domestic farm animals is subject to biochemical changes brought about by multiple factors, including husbandry practices, production demands and disease, which may ultimately impair oocyte quality and subsequent embryo development. The lactating dairy cow appears to be particularly challenged in this respect and many investigations have been carried out to characterize the underlying physiology and to identify biomarkers and indicators in readily accessible body fluids. The use of metabolomics-based techniques has identified biomarkers in follicular fluid and is being expanded for oocyte and embryo selection.
\end{abstract}

\section{Introduction}

Fertility can be defined as the natural capability to produce offspring. In cattle, a number of metrics exist by which "fertility rate" is reported, including the number of days open, or calving to conception interval, and pregnancy rate to first and/or subsequent services. Regardless of the variation in measures of reproductive success, pregnancy is the endpoint and it is the culmination of precisely ordered, well-orchestrated events, which commence with the timely resumption of ovarian activity post-calving. The onset of cyclicity should initially result in the selection and growth of a healthy follicle that encloses a competent oocyte, and ultimately in, oestrus, ovulation, fertilization and uterine attachment by a viable embryo (Leroy et al. 2011). The concomitant development of a functional corpus luteum should provide an appropriate environment, through optimal progesterone secretion, in which the embryo can grow and develop (Diskin \& Morris 2008). The decline in fertility in high-yielding dairy cows has been reviewed extensively (Lucy 2007, Wathes et al. 2007, Diskin \& Morris 2008, Diskin et al. 2011, Wathes 2012). The lactating dairy cow appears to be challenged in particular by high-energy requirements for milk production simultaneous with inadequate feed intake, which results in the cow falling in to a state of negative energy balance (NEB), which has a dramatic impact on her fertility (Leroy et al. 2008a,b, Walsh et al. 2011). Although, characterized by a substantially smaller body of literature, there is also evidence of declining fertility in beef females, primarily evidenced by a decrease in calves per cow per year, and an increase in calving interval and age at first calving. The main factors influencing reproductive efficiency in beef cattle include age at puberty and first conception, duration of post-partum anoestrus and total lifetime productivity (Burns et al. 2010). Evidence suggests that the switch to later maturing genetics is increasing the age and weight of heifers at puberty; selection for low residual feed intake results in selection of leaner heifers that reach puberty at older ages and calve later in their first and subsequent 
calving seasons (Berry \& Crowley 2012, Randel \& Welsh 2013). Additionally, genetic selection for growth and carcass traits within beef breeding programs has had a negative genetic effect on cow fertility (Crowley et al. 2011).

\section{Where is the problem?}

Oocyte/embryo: Evidence for a contribution of poor oocyte quality to infertility comes primarily from embryo transfer studies which have reported higher pregnancy rates in lactating dairy cows after embryo transfer compared with Al (Putney et al. 1989, Ambrose et al. 1999, Rutledge 2001, Al-Katanani et al. 2002, Vasconcelos et al. 2006, Demetrio et al. 2007). These findings are substantiated by data from nonsurgical flushing of unstimulated dairy cows, which suggest that, a significant proportion of embryos degenerate before the blastocyst stage (reviewed by (Sartori et al. 2010). For example, in three studies by Cerri et al. (2009a,b,c), the proportion of viable embryos recovered on Days 6-7 was approximately 50\%. Given that fertilization rate is estimated at $85-95 \%$, a $50 \%$ viable embryo recovery rate suggests that a significant proportion of embryos are lost as early as Day 7 . The data from in vitro studies in UCD examining the effect of lactation on oocyte quality are more conflicting. For example, Snijders et al. (2000) reported lower cleavage and blastocyst rates following in vitro embryo production (IVP) of oocytes recovered from dairy cows with a higher genetic merit for milk production compared to developmental rates of oocytes from cows of average genetic merit. In contrast, Rizos et al. (2005) reported no difference in the proportion of good quality oocytes undergoing fertilization and development to the blastocyst stage between lactating cows and heifers. Similarly, Matoba et al. (2012), failed to demonstrate an effect of metabolic status postpartum on oocyte ability to undergo IVF and develop to the blastocyst stage in vitro.

Embryo/Reproductive tract: The findings of the studies listed above do not eliminate a role for the embryo or reproductive tract environment; a sub-optimal uterine environment is likely to be a major contributor to the higher incidence of early embryonic death found in repeatbreeder cows (Hill \& Gilbert 2008). Two recent studies carried out in UCD compared embryo development rates in lactating and non-lactating animals. Both studies reported lower rates of embryo development to the blastocyst stage on Day 7 in the lactating animals (Rizos et al. 2010, Maillo et al. 2012), highlighting the suboptimal uterine milieu for embryo development in lactating animals. Similar models have been described by Thompson et al. (2012) and Green et al., (2012). The sub-optimal environment is most likely due to a reduced ability to mount an effective immune response leading to a higher incidence of persistent uterine infection in dairy cows (Sheldon et al. 2006, Pyorala 2008, Wathes et al. 2009). Histological examination of the post-partum endometrium revealed that that the shallow stroma is characterized by lipid accumulation and formation of foam cells, likely a result of tissue damage after calving, bacterial infection and an influx of monocytes (Wathes et al. 2013).

Metabolic status of the transition/postpartum cow: Fluctuating concentrations of metabolites in the early postpartum period, associated with high milk production, have been strongly correlated with poor reproductive inefficiency in commercial dairy herds (Lucy 2001). Decreasing (glucose, insulin, IGF-I) or increasing (non-esterified fatty acids (NEFA), ketone bodies) circulating metabolites during nutrient partitioning associated with low body condition score (BCS) have been associated with alterations to the steroidogenic and transcriptomic profiles of ovarian follicles during their development, compared to non-lactating heifers (Bender et al. 2010, Walsh et al. 2012a,b). These differences are characterized by reduced dominant follicle estradiol and progesterone synthesis during differentiation and luteinization, and altered 
expression profiles of transcripts associated with steroid biosynthesis (Walsh et al. 2012b), immune cell function and chemotaxis (Walsh et al. 2012a). Indeed, Garverick et al., (2013) recently reported that postpartum dairy cows that became pregnant to first insemination had lower serum NEFA concentrations and greater plasma glucose concentrations compared to those that did not become pregnant. In addition, using logistic regression analysis, the authors were able to identify that NEFA and glucose concentration ratio on Day 3 postpartum had the greatest predictability of the probability of pregnancy in lactating dairy cows.

It is postulated that a better understanding of the metabolic effects of various aetiologies of subfertility may aid the development of targeted therapeutics or lead to the identification of non-invasive biomarkers for diagnostic and prognostic purposes (Baskind et al. 2011). The collection of low-molecular weight compounds ( $<1500$ Daltons) in an organism or biological sample is defined as the 'metabolome' (Wishart 2007). Low-molecular weight metabolites represent the intermediates or end products of the cell's regulatory processes; their individual profile is a referred to as a 'metabolic fingerprint' (Kell 2005). Since the metabolome is related to an organism's genotype, physiology and environment, it provides a powerful tool to assess the physiological state and to assist in the identification of possible biomarkers for fertility research (Baka \& Malamitsi-Puchner 2006, Sinclair et al. 2008).

\section{Metabolomics studies of follicular fluid}

The effect of lactation

The metabolic alterations induced by postpartum NEB have been associated with anoestrus, poor follicle growth, poor-quality oocytes, inadequate corpus luteum function, reduced steroidogenesis and compromised immune function. The oocytes that are ovulated 2-4 months after calving, at a time when breeding is normally carried out in seasonal systems, have completed their growth phase when NEB is at its most severe. Some studies have indicated that increased concentrations of NEFA and $\beta$-hydroxybutyrate (BHB) in follicular fluid adversely affect oocyte quality (Leroy et al. 2004, Leroy et al. 2005). In addition, NEFA have been shown to reduce steroidogenesis and proliferation in follicular thecal cells (Vanholder et al. 2005). Leroy et al. (2005) determined the NEFA concentration and composition in follicular fluid of high-yielding dairy cows in relation to serum early and late postpartum and subsequently added the 3 predominant NEFA (oleic, palmitic, stearic) in follicular fluid during oocyte maturation in vitro. Both palmitic and stearic acid had a negative effect on meiotic maturation, fertilization and blastocyst formation. Marei et al. (Marei et al. 2012) found that bovine oocyte maturation in the presence of added linoleic acid influenced the distribution and function of mitochondria in the cytoplasm: The authors reported that the redistribution of oocyte mitochondria from a peripheral to a diffuse pattern was delayed and the proportion of oocytes presenting clusters of mitochondria in the perinuclear region was reduced, in addition, mitochondrial inner membrane potential was decreased, while reactive oxygen species levels were increased. Van Hoeck et al. (2011) demonstrated that exposure to high concentrations of the NEFAs, oleic acid, palmitic acid and stearic acid, during oocyte maturation appeared to reduce resulting embryo quality. Exposure to elevated NEFA concentrations resulted in blastocysts with altered DNMT3A, SLC2A1 and IGF2R mRNA expression, lower cell number and increased apoptotic cell ratio in comparison to control blastocysts.

Applying metabolomic profiling to further investigate the potential of this technology as a predictor of cow fertility or oocyte quality, the metabolomic profiles of blood serum and follicular fluid from post partum lactating dairy cows and heifers were analysed and compared 
(Bender et al. 2010). Samples were collected from cows and heifers over three phases of the oestrous cycle, corresponding to stages of follicle development: newly selected dominant follicles, preovulatory follicles prior to oestrus and peri-ovulatory follicles and were analysed using gas chromatography mass spectrometry (GC-MS)-based metabolomics. Follicular fluid samples from cows contained higher levels of total saturated fatty acids (SFA) and monounsaturated fatty acids (MUFA). In particular, the concentrations of SFA, such as palmitic acid and stearic acid, were dramatically higher in the cow follicular fluid, whereas concentrations of the polyunsaturated omega-3 fatty acid, docosahexaenoic acid, were higher in heifer follicular fluid. In contrast, although the metabolic profile of serum from the lactating dairy cows was, as expected, characterized by lower insulin, IGF-1 and glucose concentrations and higher BHB concentrations compared to heifers, total SFA and MUFA levels were not different. Although each fatty acid that was different in cow serum compared to heifer serum was also different in the follicular fluid, their concentrations and ratios were generally not the same and there were additional differing fatty acids in the follicular fluid, revealing the particularly unique lipid composition of follicular fluid and highlighting the impact of the metabolic activity of follicular cells on its composition (Bender et al. 2010). Thus extrapolating serum metabolomic data to draw inferences on the ovarian environment and predict oocyte quality, while highly desirable is not readily achievable.

More recently, we profiled the follicular metabolome of cows at regular timepoints post partum (O'Doherty et al. 2014). Regardless of stage post partum the most abundant fatty acids in the follicular fluid were linoleic acid, oleic acid and stearic acid. Interestingly, analysis of bovine, ovine and porcine oocyte fatty acid composition also identified these and palmitic acid as the most abundant (McEvoy et al. 2000). Temporal differences were identified in the concentrations of several fatty acids and amino acids, although there were no distinct fatty acid profiles for lactating cows at particular time points post partum (O'Doherty et al. 2014). The abundance of valine and leucine increased significantly in follicular fluid with increasing days postpartum, whereas concentrations of creatinine and ornithine decreased. Alterations to branched chain amino acids levels have previously been implicated in insulin resistance and the development of metabolic syndromes, such as type II diabetes, hyperglycaemia, hypertension and obesity (Adeva et al. 2012, Nagata et al. 2013), conditions that are associated with poor fertility. Therefore, the profiles of branched chain fatty acids in the follicular fluid of postpartum cows may be reflective of their compromised metabolic status and may potentially indicate the competence of the oocyte within.

\section{Follicular metabolomic bio-markers: In vitro fertilization}

The selection of oocytes or embryos with the highest developmental potential is critical to successful in vitro embryo production (IVP) routines. Follicular fluid is superfluous to the IVP regime and provides a substrate for non-invasive assessment of oocyte quality (Revelli et al. 2009). Using an established individual oocyte IVP system, which permits the tracking of bovine oocytes as they progress through IVP, but avoids the low development rates associated with single oocyte culture (Matoba et al. 2010), we recently analysed the steroidal and metabolomic profiles of bovine follicular fluid from 6-8 $\mathrm{mm}$ antral follicles from which a competent oocyte had been retrieved compared to fluid from follicles associated with oocytes of low developmental potential (Matoba et al. 2013). Although there was no association of follicular testosterone, progesterone or oestradiol concentrations with the oocyte's ability to form a blastocyst in 
vitro, the profiles of quantified aqueous metabolites in follicular fluid were different between oocytes that formed blastocysts and oocytes that degenerated. In agreement with a previous report (Sinclair et al. 2008), follicular fluid L-alanine, glycine and L-glutamate concentrations were positively correlated with and therefore potentially predictive of, blastocyst formation, whereas urea was negatively correlated. Several studies have described the beneficial effects of alanine (Cetica et al. 2003) and L-alanine and glycine (Lee \& Fukui 1996) on embryonic development. Follicular fluid associated with competent oocytes was significantly lower in palmitic acid and total fatty acids and significantly higher in n-3 PUFA linolenic acid than follicular fluid from incompetent oocytes. Interestingly, higher linolenic acid was also noted in follicular fluid from heifers compared to lactating cows in the study highlighted above. In contrast, the detrimental effects of increased palmitic acid in follicular fluid, or, following addition to in vitro maturation (IVM), have been described above. Similarly, metabolomic profiles of follicular fluid from women undergoing in vitro fertilization (IVF) treatment has also revealed a negative correlation between levels of saturated fatty acids (Haggarty et al. 2006), particularly lignoceric acid, palmitic acid and arachidic acid (O'Gorman et al. 2013), with developmental outcome, and a positive correlation of docosahexaenoic acid (DHA) and of stearic acid with developmental outcome (O'Gorman et al. 2013). Multivariate statistical analysis of the data from different studies concerning the follicular metabolome indicate the high predictive ability of aqueous metabolites (Matoba et al., 2013) and fatty acids (O'Gorman et al. 2013), according to the model and species used.

Follicular metabolomic bio-markers: High and low cow fertility model

Most recently, we have applied metabolomic profiling of follicular fluid to search for biomarkers of cow fertility (Moore et al. 2013), using a genetic model of Holstein dairy cow fertility established in Teagasc Moorepark (Cummins et al. 2012a,b,c). The model was composed of two groups of cows with similar genetic merit for milk production traits, but with extremes of good (Fert + ) or poor (Fert-) genetic merit for fertility traits. The metabolomes of follicular fluid of the first wave dominant follicle and blood serum on $\mathrm{d} 7 \mathrm{\text {of }}$ the oestrous cycle was compared in the Fert + and Fert- cows. Following analysis, there was clear separation of the Fert- and Fert + cows based on the concentrations of follicular fluid fatty acid, highlighting the potential of this technology as a predictor or biomarker of cow fertility. Interestingly and in keeping with the earlier mentioned findings of Bender et al. (2010), although the serum fatty acid profiles were also different, their predictive power was not as robust, again highlighting the unique metabolic milieu of the ovarian follicle. A summary of the key follicular fluid and serum metabolites associated with oocyte competence and cow fertility are presented in Table 1.

\section{Conclusion}

The follicular fluid metabolome provides a greater potential for predicting cow fertility and oocyte competence than other readily accessible body fluids such as milk and blood. However, caution must be exercised when interpreting the results, as the data are model specific. 
Table 1: Summary of metabolomic data associated with oocyte competence or cow fertility

\begin{tabular}{|c|c|c|c|c|}
\hline Matrix & Association & Positive association & Negative association & Reference \\
\hline \multirow{21}{*}{$\begin{array}{l}\text { Follicular } \\
\text { fluid }\end{array}$} & \multirow{11}{*}{$\begin{array}{l}\text { Oocyte } \\
\text { competence }\end{array}$} & DHA (C22:6n3) & Palmitic acid (C16:O) & \multirow[t]{4}{*}{ O'Gorman et al., 2013} \\
\hline & & Stearic acid (C18:O) & Linoceric acid (C16:O) & \\
\hline & & & Arachidic acid (C20:O) & \\
\hline & & Total PUFA & Total SFA & \\
\hline & & Linolenic acid (C18:2n6) & Palmitic acid (C16:O) & \multirow[t]{5}{*}{ Matoba et al., 2013} \\
\hline & & & Total SFA & \\
\hline & & L-alanine & Urea & \\
\hline & & Glycine & & \\
\hline & & L-Glutamate & & \\
\hline & & & Palmitic acid (C16:0) & \multirow[t]{2}{*}{ Leroy et al., 2005} \\
\hline & & & Stearic acid (C18:0) & \\
\hline & \multirow[t]{10}{*}{ Cow Fertility } & & Myristic (C14:0) & \multirow[t]{5}{*}{ Bender et al., 2010} \\
\hline & & & Palmitoleic (C16:1) & \\
\hline & & & Palmitic (C16:0) & \\
\hline & & & $\gamma$-Linolenic (C18:3n6) & \\
\hline & & & Linoleic (C18:2n6) & \\
\hline & & & Myristoleic (C14:1) & \multirow[t]{5}{*}{ Moore et al., 2013} \\
\hline & & & Heptadecenoic (C17:1) & \\
\hline & & & Myristic (C14:0) & \\
\hline & & & $\gamma$-Linolenic (C18:3n6) & \\
\hline & & & Arachidic acid (C20:O) & \\
\hline \multirow[t]{4}{*}{ Blood } & & DHA (C22:6n3 & Palmitic acid (C16:0) & \multirow[t]{3}{*}{ Bender et al., 2010} \\
\hline & & DGLA (C20:3n6) & Linoleic acid (C18:2n6) & \\
\hline & & Total PUFA & (n-6) PUFA & \\
\hline & & & Total NEFA & Garverick et al., 2013 \\
\hline
\end{tabular}

DHA:Docosahexanoic acid; PUFA: Polyunsaturated fatty acids; SFA: saturated fatty acids; DGLA: Dihomo- $\gamma-$ linolenic acid; NEFA: Non esterified fatty acids

\section{References}

Adeva MM, Calvino J, Souto G \& Donapetry C 2012 Insulin resistance and the metabolism of branched-chain amino acids in humans. Amino Acids 43 171-181.

Al-Katanani YM, Drost M, Monson RL, Rutledge JJ, Krininger CE, 3rd, Block J, Thatcher WW \& Hanse PJ 2002 Pregnancy rates following timed embryo transfer with fresh or vitrified in vitro produced embryos in lactating dairy cows under heat stress conditions. Theriogenology 58 171-182.

Ambrose JD, Drost M, Monson RL, Rutledge JJ, LeibfriedRutledge ML, Thatcher MJ, Kassa T, Binelli M, Hansen PJ, Chenoweth PJ \& Thatcher WW 1999 Efficacy of timed embryo transfer with fresh and frozen in vitro produced embryos to increase pregnancy rates in heat-stressed dairy cattle. J Dairy Sci 82 2369-2376.

Baka S \& Malamitsi-Puchner A 2006 Novel follicular fluid factors influencing oocyte developmental potential in IVF: a review. Reproductive Biomedicine Online 12 500-506.

Baskind NE, Mcrae C, Sharma V \& Fisher J 2011 Understanding subfertility at a molecular level in the female through the application of nuclear magnetic resonance (NMR) spectroscopy. Human Reproduction Update 17 228-241.

Bender K, Walsh S, Evans AC, Fair T \& Brennan L 2010a Metabolite concentrations in follicular fluid may explain differences in fertility between heifers and lactating cows. Reproduction 139 1047-1055.

Berry DP \& Crowley JJ 2012 Residual intake and body weight gain: a new measure of efficiency in growing cattle. J Anim Sci 90 109-115.

Burns BM, Fordyce G \& Holroyd RG 2010 A review of factors that impact on the capacity of beef cattle females to conceive, maintain a pregnancy and wean a calfImplications for reproductive efficiency in northern Australia. Anim Reprod Sci 122 1-22.

Cerri RL, Juchem SO, Chebel RC, Rutigliano HM, Bruno RG, Galvao KN, Thatcher WW \& Santos JE 2009a Effect of fat source differing in fatty acid profile on metabolic parameters, fertilization, and embryo quality in high-producing dairy cows. J Dairy Sci 92 1520-1531.

Cerri RL, Rutigliano HM, Chebel RC \& Santos JE 2009b Period of dominance of the ovulatory follicle influences 
embryo quality in lactating dairy cows. Reproduction 137 813-823.

Cerri RL, Rutigliano HM, Lima FS, Araujo DB \& Santos JE 2009c Effect of source of supplemental selenium on uterine health and embryo quality in high-producing dairy cows. Theriogenology 71 1127-1137.

Cetica P, Pintos L, Dalvit G \& Beconi M 2003 Involvement of enzymes of amino acid metabolism and tricarboxylic acid cycle in bovine oocyte maturation in vitro. Reproduction 126 753-763.

Crowley JJ, Evans RD, Mc Hugh N, Kenny DA, McGee M, Crews DH, Jr. \& Berry DP 2011 Genetic relationships between feed efficiency in growing males and beef cow performance. J Anim Sci 89 3372-3381.

Cummins SB, Lonergan P, Evans ACO, Berry DP, Evans RD \& Butler ST 2012a Genetic merit for fertility traits in Holstein cows: I. Production characteristics and reproductive efficiency in a pasture-based system. Journal of dairy science 95 1310-1322.

Cummins SB, Lonergan P, Evans ACO \& Butler ST 2012b Genetic merit for fertility traits in Holstein cows: II. Ovarian follicular and corpus luteum dynamics, reproductive hormones, and estrus behavior. Journal of dairy science 95 3698-3710.

Cummins SB, Waters SM, Evans ACO, Lonergan P \& Butler ST 2012C Genetic merit for fertility traits in Holstein cows: III. Hepatic expression of somatotropic axis genes during pregnancy and lactation. Journal of dairy science 95 3711-3721.

Demetrio DG, Santos RM, Demetrio CG \& Vasconcelos JL 2007 Factors affecting conception rates following artificial insemination or embryo transfer in lactating Holstein cows. J Dairy Sci 90 5073-5082.

Diskin MG \& Morris DG 2008 Embryonic and early foetal losses in cattle and other ruminants. Reprod Domest Anim 43 Suppl 2 260-267.

Diskin MG, Parr MH \& Morris DG 2011 Embryo death in cattle: an update. Reprod Fertil Dev 24 244-251.

Garverick HA, Harris MN, Vogel-Bluel R, Sampson JD, Bader J, Lamberson WR, Spain JN, Lucy MC \& Youngquist RS 2013 Concentrations of nonesterified fatty acids and glucose in blood of periparturient dairy cows are indicative of pregnancy success at first insemination. J Dairy Sci 96 181-188.

Green JC, Meyer JP, Williams AM, Newsom EM, Keisler DH \& Lucy MC 2012 Pregnancy development from day 28 to 42 of gestation in postpartum Holstein cows that were either milked (lactating) or not milked (not lactating) after calving. Reproduction 143 699-711.

Haggarty P, Wood M, Ferguson E, Hoad G, Srikantharajah A, Milne E, Hamilton M \& Bhattacharya S 2006 Fatty acid metabolism in human preimplantation embryos. Hum Reprod 21 766-773.

Hill J \& Gilbert R 2008 Reduced quality of bovine embryos cultured in media conditioned by exposure to an inflamed endometrium. Aust Vet / 86 312-316.

Kell DB 2005 Metabolomics, machine learning and modelling in systems biology: Towards an understanding of the language of cells. Journal of Biotechnology 118 S5-S5.
Lee ES \& Fukui Y 1996 Synergistic effect of alanine and glycine on bovine embryos cultured in a chemically defined medium and amino acid uptake by vitroproduced bovine morulae and blastocysts. Biol Reprod 55 1383-1389.

Leroy JL, Opsomer G, Van Soom A, Goovaerts IG \& Bols PE 2008a Reduced fertility in high-yielding dairy cows: are the oocyte and embryo in danger? Part I. The importance of negative energy balance and altered corpus luteum function to the reduction of oocyte and embryo quality in high-yielding dairy cows. Reprod Domest Anim 43 612-622.

Leroy JL, Rizos D, Sturmey R, Bossaert P, Gutierrez-Adan A, Van Hoeck V, Valckx S \& Bols PE 2011 Intrafollicular conditions as a major link between maternal metabolism and oocyte quality: a focus on dairy cow fertility. Reprod Fertil Dev 24 1-12.

Leroy JL, Van Soom A, Opsomer G, Goovaerts IG \& Bols PE 2008b Reduced fertility in high-yielding dairy cows: are the oocyte and embryo in danger? Part II. Mechanisms linking nutrition and reduced oocyte and embryo quality in high-yielding dairy cows. Reprod Domest Anim $\mathbf{4 3}$ 623-632.

Leroy JL, Vanholder T, Delanghe JR, Opsomer G, Van Soom A, Bols PE, Dewulf J \& de Kruif A 2004 Metabolic changes in follicular fluid of the dominant follicle in highyielding dairy cows early post partum. Theriogenology 62 1131-1143.

Leroy JL, Vanholder T, Mateusen B, Christophe A, Opsomer G, de Kruif A, Genicot G \& Van Soom A 2005 Nonesterified fatty acids in follicular fluid of dairy cows and their effect on developmental capacity of bovine oocytes in vitro. Reproduction 130 485-495.

Lucy MC 2001 Reproductive loss in high-producing dairy cattle: where will it end? J Dairy Sci 84 1277-1293.

Lucy MC 2007 Fertility in high-producing dairy cows: reasons for decline and corrective strategies for sustainable improvement. Soc Reprod Fertil Suppl 64 237-254.

Maillo V, Rizos D, Besenfelder U, Havlicek V, Kelly AK, Garrett M \& Lonergan P 2012 Influence of lactation on metabolic characteristics and embryo development in postpartum Holstein dairy cows. J Dairy Sci 95 38653876.

Marei WF, Wathes DC \& Fouladi-Nashta AA 2012 Differential effects of linoleic and alpha-linolenic fatty acids on spatial and temporal mitochondrial distribution and activity in bovine oocytes. Reprod Fertil Dev $\mathbf{2 4}$ 679-690.

Matoba S, Bender K, Fahey AG, Mamo S, Brennan L, Lonergan P \& Fair T 2013 Predictive value of bovine follicular components as markers of oocyte developmental potential. Reproduction Fertility and Development 26 337-345.

Matoba S, Fair T \& Lonergan P 2010 Maturation, fertilisation and culture of bovine oocytes and embryos in an individually identifiable manner: a tool for studying oocyte developmental competence. Reproduction Fertility and Development 22 839-851.

Matoba S, O'Hara L, Carter F, Kelly AK, Fair T, Rizos D \& Lonergan P 2012 The association between metabolic 
parameters and oocyte quality early and late postpartum in Holstein dairy cows. J Dairy Sci 95 1257-1266.

McEvoy TG, Coull GD, Broadbent PJ, Hutchinson JSM \& Speake BK 2000 Fatty acid composition of lipids in immature cattle, pig and sheep oocytes with intact zona pellucida. Journal of Reproduction and Fertility 118 163-170.

Moore SG, O'Gorman A, Brennan L, Evans ACO, Lonergan P, Fair T \& Butler ST. 2013. The effect of genetic merit for fertility traits on the follicular fluid and serum metabolome of dairy cows. In Agricultural Research Forum, pp. 19.

Nagata C, Nakamura K, Wada K, Tsuji M, Tamai Y \& Kawachi T 2013 Branched-chain Amino Acid Intake and the Risk of Diabetes in a Japanese Community The Takayama Study. American Journal of Epidemiology 178 1226-1232.

O'Doherty AM, AI Naib A, O'Gorman A, Brennan L, Daly E, Duffy P \& Fair T 2014 Failure to imprint: hypomethylation trends at imprinted loci in oocytes recovered from postpartum dairy cows. under review.

O'Gorman A, Wallace M, Cottell E, Gibney MJ, McAuliffe FM, Wingfield M \& Brennan L 2013 Metabolic profiling of human follicular fluid identifies potential biomarkers of oocyte developmental competence. Reproduction 146 389-395.

Putney DJ, Drost M \& Thatcher WW 1989 Influence of summer heat stress on pregnancy rates of lactating dairy cattle following embryo transfer or artificial insemination. Theriogenology 31 765-778.

Pyorala S 2008 Mastitis in post-partum dairy cows. Reprod Domest Anim 43 Suppl 2 252-259.

Randel RD \& Welsh TH, Jr. 2013 Joint Alpharma-Beef Species Symposium: interactions of feed efficiency with beef heifer reproductive development. J Anim Sci 91 1323-1328.

Revelli A, Delle Piane L, Casano S, Molinari E, Massobrio M \& Rinaudo P 2009 Follicular fluid content and oocyte quality: from single biochemical markers to metabolomics. Reproductive Biology and Endocrinology 7.

Rizos D, Burke L, Duffy P, Wade M, Mee JF, O'Farrell KJ, Macsiurtain M, Boland MP \& Lonergan P 2005 Comparisons between nulliparous heifers and cows as oocyte donors for embryo production in vitro. Theriogenology 63 939-949.

Rizos D, Carter F, Besenfelder U, Havlicek V \& Lonergan P 2010 Contribution of the female reproductive tract to low fertility in postpartum lactating dairy cows. J Dairy Sci 93 1022-1029.

Rutledge JJ 2001 Use of embryo transfer and IVF to bypass effects of heat stress. Theriogenology 55 105-111.

Sartori R, Bastos MR \& Wiltbank MC 2010 Factors affecting fertilisation and early embryo quality in single- and superovulated dairy cattle. Reprod Fertil Dev 22 151-158.

Sheldon IM, Lewis GS, LeBlanc S \& Gilbert RO 2006 Defining postpartum uterine disease in cattle. Theriogenology 65 1516-1530.

Sinclair KD, Lunn LA, Kwong WY, Wonnacott K, Linforth RST \& Craigon J 2008 Amino acid and fatty acid composition of follicular fluid as predictors of in-vitro embryo development. Reproductive Biomedicine Online 16 859-868.

Snijders SE, Dillon P, O'Callaghan D \& Boland MP 2000 Effect of genetic merit, milk yield, body condition and lactation number on in vitro oocyte development in dairy cows. Theriogenology 53 981-989.

Thompson IM, Cerri RL, Kim IH, Ealy AD, Hansen PJ, Staples CR \& Thatcher WW 2012 Effects of lactation and pregnancy on metabolic and hormonal responses and expression of selected conceptus and endometrial genes of Holstein dairy cattle. J Dairy Sci 95 5645-5656.

Van Hoeck V, Sturmey RG, Bermejo-Alvarez P, Rizos D, Gutierrez-Adan A, Leese HJ, Bols PE \& Leroy JL 2011 Elevated non-esterified fatty acid concentrations during bovine oocyte maturation compromise early embryo physiology. PLoS One 6 e23183.

Vanholder T, Leroy JL, Soom AV, Opsomer G, Maes D, Coryn M \& de Kruif A 2005 Effect of non-esterified fatty acids on bovine granulosa cell steroidogenesis and proliferation in vitro. Anim Reprod Sci 87 33-44.

Vasconcelos JL, Demetrio DG, Santos RM, Chiari JR, Rodrigues CA \& Sa Filho OG 2006 Factors potentially affecting fertility of lactating dairy cow recipients. Theriogenology 65 192-200.

Walsh SW, Fair T, Browne JA, Evans AC \& McGettigan PA 2012a Physiological status alters immunological regulation of bovine follicle differentiation in dairy cattle. J Reprod Immunol 96 34-44.

Walsh SW, Mehta JP, McGettigan PA, Browne JA, Forde N, Alibrahim RM, Mulligan FJ, Loftus B, Crowe MA, Matthews D, Diskin M, Mihm M \& Evans AC 2012b Effect of the metabolic environment at key stages of follicle development in cattle: focus on steroid biosynthesis. Physiol Genomics 44 504-517.

Walsh SW, Williams EJ \& Evans AC 2011 A review of the causes of poor fertility in high milk producing dairy cows. Anim Reprod Sci 123 127-138.

Wathes DC 2012 Mechanisms linking metabolic status and disease with reproductive outcome in the dairy cow. Reprod Domest Anim 47 Suppl 4 304-312.

Wathes DC, Cheng Z, Chowdhury W, Fenwick MA, Fitzpatrick R, Morris DG, Patton J \& Murphy JJ 2009 Negative energy balance alters global gene expression and immune responses in the uterus of postpartum dairy cows. Physiol Genomics 39 1-13.

Wathes DC, Clempson AM \& Pollott GE 2013 Associations between lipid metabolism and fertility in the dairy cow. Reproduction Fertility and Development 25 48-61.

Wathes DC, Fenwick M, Cheng Z, Bourne N, Llewellyn S, Morris DG, Kenny D, Murphy J \& Fitzpatrick R 2007 Influence of negative energy balance on cyclicity and fertility in the high producing dairy cow. Theriogenology 68 Suppl 1 S232-241.

Wishart DS 2007 Proteomics and the human metabolome project. Expert Review of Proteomics 4 333-335. 